\title{
Globalisation, Liberalisation, and Equitable Growth: Lessons from Contemporary Asian Experience
}

\author{
AZIZUR RAHMAN KHAN
}

\section{INTRODUCTION: EXPECTED OUTCOME OF INTEGRATION WITH THE GLOBAL ECONOMY}

Since the beginning of the 1980s the less developed countries (LDCs) have been getting integrated with the global economy at a rapidly accelerating rate. The impetus for the process came from the need to make adjustment in the unsustainable imbalance in the external account that most of these countries experienced in the aftermath of the oil shocks of the 1970s and the declining demand for their exports due to the recession in the OECD countries during the 1980s. Many of these countries had to subject themselves to structural adjustment programmes at the behest of the multilateral donor agencies, led by the World Bank and the International Monetary Fund, who emphasised the urgency of reforming the protectionist trade regimes of these countries. Simultaneously, these countries came to realise the inefficiency of resource use fostered by their past strategy of import-substituting industrialisation (ISI) characterised by a trade and investment regime that enshrined overvalued exchange rates, quantitative import controls, high and non-uniform rates of effective protection, discrimination against export and strong impediments to foreign direct investment.

The reform programme that these countries gradually implemented during the 1980s and the early 1990s dismantled many of the components of the ISI strategy. The extent of dependence on quantitative import controls was sharply curtailed. The exchange rate came to be increasingly determined by market forces. The rates of tariff were brought down. The discrimination against exports, relative to import substitutes, was reduced. There was also a sharp reduction in restrictions to which foreign direct investment had been subjected in the past. The reform of trade and foreign investment was of course often accompanied by many other reforms, notably a general reduction of direct regulation of prices and distribution; a generally greater dependence on the market; and a reduction in the public ownership of means of production in favour of the 
private sector. In the former centrally-planned countries, e.g., China and Vietnam, these reforms represented a fundamental reversal of the former socialist system of ownership and distribution.

A primary focus of the reform of the trade and investment regime, and the reform programme in general, was to promote a greater integration of the LDC economies with the global economy. It was expected, as indicated by economic theory, that the reduction of impediments to free trade would make the structure of production in LDCs more consistent with their comparative advantage than before. This would encourage the expansion of production and export of goods and services which could be produced at relatively low cost in terms of LDC resources and the replacement of domestic production by the import of those goods and services which were costly in terms of LDC resources to produce. As a result the rate of growth would be higher due to improved efficiency of resource use.

A further impetus to higher growth was expected to come from an increased flow of foreign direct investment. Its great attraction to the LDCs is that it not only augments their investible resources, but also provides access to other scarce resources, notably technology, management and marketing.

Greater integration with the global economy was also expected to improve the distribution of income and reduce poverty. Quite apart from the increased scope for poverty reduction that higher growth would provide, an increased dependence on comparative advantage was expected to promote specialisation in goods and services that would use the abundant LDC resource, labour, more intensively. This would increase the rate of growth of productive employment which is the most effective and efficient instrument for poverty reduction.

The above expectation, based on economic theory, was reinforced by the actual performance of the rapidly growing East Asian countries, e.g., the Republic of Korea, Taiwan, Hong Kong, and Singapore, to name the first-tier of the East Asian "tigers". These countries not only achieved historically unprecedented rates of growth, but also succeeded in reducing poverty and avoiding a significant rise in inequality in the distribution of income. The most convincing of these evidences is available for Korea for which 14 observations of the Gini ratio are available over 35 years (1953 to 1988) and they show no trend whatsoever. ${ }^{1}$ While such a long time series of Gini ratio is not readily available for Taiwan, available evidence suggests that the trend in inequality in Taiwan has not been different from that in Korea. Estimates for Hong Kong show no rise in the Gini ratio until after 1980 and for Singapore there is no trend in the Gini ratio over the 1970s and the 1980s. ${ }^{2}$ All these countries successfully reduced the incidence of absolute poverty to insignificant rates by any reasonable standard of poverty threshold. They all have graduated to the category of "high-income countries" according to the

${ }^{1}$ These are reported in World Bank (1997).

${ }^{2}$ These data are also reported in World Bank (1997). 
World Bank classification, the last of them, Korea, achieving that status in 1995.

In recent years, there has been a significant evolution in the characterisation of the development strategy of these countries. By now there is widespread agreement among development analysts that the experience of these countries can not be put in the category of laissez-faire strategies based on free trade and free market. There is however little disagreement that these countries indeed followed an outward-looking strategy in that they did not discriminate against exports and aggressively took advantage of the global market especially as a market for exports and a source of technology (and also investment in the case of some, though not all).

The East Asian experience was interpreted as an evidence in practice of what orthodox economic theorising has long stood for: development policies based on economic liberalisation and integration with the global economy would lead to the happy combination of rapid growth, avoidance of distributive inequality and a quick reduction in the incidence of poverty. The replication of the East Asian strategy, thus interpreted, has come to be the new orthodoxy in development policy. Thus, for example, the Asian Development Bank, in its recent major study Emerging Asia:Changes and Challenges, states that by improving their policy reform to the "East Asian standard" the contemporary Asian LDCs should be able to achieve substantially higher growth with equity. ${ }^{3}$ The presumption is that the distributional outcome of the strategy in contemporary Asian LDCs will be similar to that in the historical case of East Asia. Recent crisis in some East Asian countries has led to questions and controversies about certain aspects of their development policies; but the above evaluation of the efficiency and equity outcome of their export-oriented strategy of integration with the global economy has not been seriously challenged.

Pakistan had long been reforming its economic policies and institutions to promote greater openness. In 1987 it committed itself to a comprehensive programme of structural reform to liberalise its economic policies and to accelerate the pace of integration with the global economy. Whether these reforms have produced the expected growth and distributional outcome is a question that has preoccupied the social scientists in the country ever since. That these reforms have been followed by a period of slower growth is very well documented. Some recent studies [e.g., Amjad and Kemal (1996)] have convincingly argued that these reforms also had an adverse distributional outcome. The purpose of this paper is to show that Pakistan is by no means alone in facing these unexpected outcomes. The paper also asks why the actual outcome has been so very different from what economic theory and past empirical experience led one to expect. It finally addresses the question whether a better outcome might have been achieved if reforms for integration with the global economy were complemented by additional policies.

${ }^{3}$ See Asian Development Bank (1997). 


\section{THE ASYMMETRY BETWEEN EXPECTED AND ACTUAL OUTCOME}

After more than a decade and a half of persistence with reforms, leading to greater integration with the global economy, most LDCs find themselves faced with an outcome which is substantially at variance with the above expectation. Much of the developing world has been marginalised in terms of growth of output and trade as the world economy has become increasingly globalised. Sub-Saharan Africa experienced a reduction in per capita income and in its share of world trade during the era of globalisation. ${ }^{4}$ The former Soviet Union and Eastern Europe, in which the process of reform and integration with the global economy began later, also experienced a reduction in per capita income, often at very high rates. Latin America and the Caribbean region experienced a reduction in per capita income during the decade of the 1980s and only a slow recovery in per capita income during the first half of the 1990s. In most countries of all these regions the distribution of income worsened and/or the incidence of poverty increased. Needless to say that there are isolated cases of countries in these regions which have achieved outcomes that are different from the regional trends. ${ }^{5}$

Developing Asia is the only region which achieved an acceleration in growth in GNP during the period of globalisation. East and South-East Asia grew at 7.6 percent per year during the 1980s and at a historically unprecedented 10.3 percent during the first half of the 1990s. The rates of growth in South Asia during these periods were respectively 5.7 percent and 4.6 percent. $^{6}$

For both these regions growth rates during the era of increased globalisation were higher than the growth rates achieved in the period before 1980. These regions also achieved an increase in their share of world trade. ${ }^{7}$

Even for these regions, the record on income distribution and poverty reduction is at best mixed. Growth has often been accompanied by a significant increase in inequality. Even in the most rapidly growing countries the benefit of growth on poverty reduction was partly offset by the effect of increasing inequality. Often growth was not rapid enough to offset the adverse effect of increasing inequality so that there was an increase in the incidence of poverty. A few examples would help illustrate the point.

China embarked on a major systemic reform in 1979 with a primary focus on the growth and reform of the rural economy. Its achievements, in terms of accelerated

${ }^{4}$ For brevity we shall often refer to the period since about 1980 as the era of globalisation. What we actually mean is that during this period there was an acceleration in the pace of globalisation, a process that had been going on for a long period prior to the 1980s.

${ }^{5}$ For evidence in support of the statements made above the reader is referred to Khan (1994) and Khan and Muqtada (eds) (1997).

${ }^{6}$ These rates of growth are from World Bank (1997).

${ }^{7}$ See Khan (1994) and Khan and Muqtada (eds) (1997) for evidence. 
growth and poverty reduction, were dramatic. By the middle of the 1980s the primary focus of China's development strategy shifted away from the rural economy towards an increased integration with the global economy. Since then China has achieved a dramatic expansion in exports and in the inflow of foreign direct investment and a further acceleration of growth in GDP. But the pace of poverty reduction declined sharply and arguably came to a halt over extended periods. ${ }^{8}$

In India, there has been a steady reduction in the incidence of poverty since the late 1960s. The reduction in poverty, however appears to have been slower in the period after 1983 than before. The Indian economy began its reform for integration with the global economy in the mid 1980s whence its growth rate increased over the historical trend rate in the preceding decades. In 1991 the process of liberalisation and reform for increased integration with the global economy accelerated in India. During the first half of the 1990s the growth rate of the economy declined sharply and the rate of poverty reduction was reversed or halted. ${ }^{9}$

Bangladesh embarked on reforms in the late 1970s and in the mid 1980s its reform of the trade regime gained increased momentum. The growth in per capita income was faster in the period after the mid-1980s than before if only because the rate of population growth appreciably declined. And yet the incidence of poverty increased in the period after the mid-1980s whereas the country had achieved a substantial reduction in the incidence of poverty in the period prior to 1985 when the rate of growth in per capita income was lower. ${ }^{10}$

Pakistan adopted a major programme of structural adjustment in the second half of the 1980s for the reform of the foreign trade regime and the promotion of greater integration with the global economy. While its record in reducing the incidence of poverty was quite satisfactory until 1987-88, the period thereafter appears to have witnessed an increase in the incidence of poverty. ${ }^{11}$ This period witnessed both a deceleration of the rate of growth of the economy and a worsening of the distribution of income.

Indeed there are countries of Asia-notably Indonesia, Malaysia and Thailandthat achieved continued poverty reduction during the era of globalisation at least until they were hit by the financial crisis of $1997 .^{12}$ Even in these countries frequently the

${ }^{8}$ For documentation see World Bank (1992) and Khan (1998).

${ }^{9}$ This is based on Tendulkar et al. (1996). Comments on the change in the rate of poverty reduction are based on the estimates of the head count rate of poverty reported in the paper.

${ }^{10}$ For a summary of evidence see Khan (1995).

${ }^{11}$ See Amjad and Kemal (1996) for evidence.

${ }^{12}$ This appears to be the case also with the Republic of Korea, Taiwan, Hong Kong and Singapore, countries which are at a much higher level of development than the Asian LDCs discussed above. Indeed, as noted above in this paper, by now all these four are high income countries according to World Bank classification [see World Bank (1997)]. This paper does not analyse the extent to which the financial crisis in selected East and South-East Asian countries in 1997 was due to the forces of globalisation and what its effects might be on income distribution and poverty. There is widespread belief that the failure to manage a particular feature of globalisation-namely the free movement of capital-was a primary cause of the crisis. While it is too early to arrive at meaningful estimates, it is clear that the distributional consequences of the crisis are certain to affect the poor adversely. 
favourable poverty outcome was accompanied by a worsening of the distribution of income, the negative effect of which was outweighed by the positive effect of very high rate of growth in output and income. It should be noted that even this outcome is in sharp contrast with the historical experience of East Asia the essence of which consists of the phenomenon that no significant part of the effect of growth on poverty reduction was offset by a worsening of the distribution of income.

The evidence by now is overwhelming that the replication of the East Asian strategy of outward-looking development, by way of greater integration with the global economy, is resulting in a distributional outcome in many contemporary Asian LDCs that is substantially different from that of the original cases. It is important to explain this difference in outcome.

\section{TOWARDS AN EXPLANATION OF IMMISERISING INTEGRATION WITH THE GLOBAL ECONOMY}

We shall identify some of the major causes why the expectation, that increased integration with the global economy would make growth in LDCs poverty-reducing, did not materialise in many cases. These causes did not always coincide although some combination of them characterised those LDCs which experienced immiserising integration with the global economy.

\section{Globalisation, Employment, and Poverty}

As already noted, the expectation that growth in a globalising world economy would alleviate poverty was based on the reasoning that increased integration with the world economy would mean an end of the notoriously employment-hostile ISI regime and change the composition of industries in favour of exports which, given the relative abundance of labour in the LDCs, are likely to consist of labour-intensive goods. The reform of the trade regime and other related incentives should facilitate this process by promoting specialisation in goods intensive in the use of abundant factors. An inflow of foreign capital, especially foreign direct investment (FDI) pursuing low real cost of labour, should provide additional impetus to employment expansion.

The experience of even the most successful cases of adjustment to globalisation is very mixed on the expansion of industrial employment. Contrary to the expectation outlined above, the output elasticity of employment in manufacturing industries fell in many countries during the period of globalisation.

In China the industrial sector had a dismal employment performance in the period of globalisation. Output elasticity of employment for the sector during 1984-94 was 0.27, only 60 percent of what it was for Korea in the same period, an economy with a 
much higher level of real wages and technology. ${ }^{13}$ But the above elasticity for China refers to all kinds of industries including the ones in rural areas. In urban industries the output elasticity of employment was as low as 0.037 for the period $1988-95 .{ }^{14}$ This low absorption of labour characterised the Chinese industries in a period of extremely rapid industrial growth and growth of manufactured exports which, according to the findings of a World Bank study, were labour intensive. ${ }^{15}$

In Vietnam the annual growth in employment in industries (including construction) during 1991-95 was 1.62 percent while output in those sectors increased at an annual rate of 13.78 percent, yielding a dismally low output elasticity of employment of $0.12 .^{16}$

Employment in Indian manufacturing industries increased at an annual rate of 3.9 percent during the 1970s. During 1980-91, despite a significant acceleration in the rate of growth of the economy, the trend rate of growth in employment in manufacturing was not significantly different from zero based on the data shown in World Bank (1995). In the Philippines the share of manufacturing industries in total employment declined a little during the period of globalisation (1980-93). ${ }^{17}$

As far as the present writer can see, the change in the magnitude of the output elasticity of employment in manufacturing in Pakistan has been far more drastic than any of the above cases in the period following the adoption of widespread reforms under 1987-88 structural adjustment programme promoting accelerated integration with the world economy. During the period 1973-85 the elasticity was 0.433 . During the period 1987-94 it fell to $-.329 .{ }^{18}$ For Pakistan, output elasticity of employment in other sectors is also reported to have fallen sharply during the period of structural adjustment. ${ }^{19}$

${ }^{13}$ For China the elasticity is estimated in Khan (1996) and Khan (1988). For the Republic of Korea the output-elasticity of employment in manufacturing industries was 0.67 during $1970-80$ and 0.45 during 1980-90. By the 1980s Korea had become a relatively high-wage economy, particularly in comparison with China during the late 1980s and the early 1990s. It would therefore appear that the elasticity for the 1970s is the relevant one for comparison with the elasticity for China during the decade of globalisation. On this basis the Chinese elasticity was only 40 percent of the Korean elasticity. The Korean elasticities, estimated from the value added and employment data reported in World Bank (1992a, 1995), are discussed in Khan (1996).

${ }^{14}$ See Khan (1998).

${ }^{15}$ See Boltho (1994).

${ }^{16}$ These estimates are based on the official data quoted in IMF (1996).

${ }^{17}$ See Khan (1997).

${ }^{18}$ These elasticities are the $b$ coefficients in the following estimated equation:

$$
\log E M P=a+b \log V A
$$

where EMP = total manufacturing employment and VA = manufacturing value added at constant 1987 prices. The values of both $b$ s are significant at 1 percent level. The data on manufacturing employment is from ILO's Yearbook of Labour Statistics (extracted from ILO DATABASE) and value-added in manufacturing is from World Bank (1997).

${ }^{19}$ See Amjad and Kemal (1996). 
How might one explain the paradox that industrialisation based on the expansion of (presumably) labour-intensive exports during the era of globalisation resulted in a reduction in the rate of growth of employment? It is particularly intriguing that this happened in spite of the fact that empirical studies show-as is illustrated in the documentation cited for China-that the growth of manufactured exports was concentrated in labour-intensive products. The present writer does not claim to have done as careful an analysis of this phenomenon as one should. Especially for Pakistan he has had little access to the details of the underlying forces leading to the dramatic shift in the elasticity of employment. Enough is however known about the circumstances in some countries to suggest a hypothesis.

The explanation of the paradox seems to lie in the initial conditions of manufacturing industries in many of these countries. The system of incentives prevailing in the period before accelerated globalisation permitted an absorption of labour far in excess of requirement in the manufacturing industries of these countries. In the case of China and Vietnam this mainly happened in state and collective enterprises and in India (and possibly Pakistan) in public sector industries. The phenomenon was very much a part of the social policies that these countries were committed to at the time. Economic reform for integration with the globalising world economy made it increasingly difficult to continue with this system of concealed social protection. Thus a process of shedding the concealed surplus labour began. The observed low output elasticity of employment hides the fact that it represents the sum of two effects: (a) a fairly high output elasticity of employment measured at constant intensity of employment per worker; and (b) a rise in the intensity of employment per worker due to a reduction of concealed unemployment in industries.

It is possible to argue that reforms leading to globalisation should not be blamed for the slow growth of employment in industries. Industrial employment, measured at constant intensity of employment per worker, has increased quite rapidly but is hidden due to the effect of the reduction in concealed surplus labour in public sector industries. Industries will become more efficient once the process of shedding surplus labour is completed. Indeed a continuation of concealed unemployment in industries is an inefficient method of protecting the workers. A proper method of protecting surplus industrial workers is to institute either a formal system of unemployment insurance or a programme of public works until the transition is completed. Both these alternatives are however hard to pursue in an environment of macroeconomic policies emphasising fiscal retrenchment which has typically been an integral part of the reform programmes.

\section{Globalisation, Stabilisation, and Poverty}

Opening up of the LDCs to the global economy was often initiated in a crisis environment in which LDCs, failing to cope with unsustainable macroeconomic imbalances, had come to swallow the bitter pill of stabilisation and structural adjustment 
peddled by donor agencies. Often the programmes of stabilisation brought the level of expenditure down to a level that actually resulted in a drastic reduction in the rate of growth of the economy, an outcome frequently obtaining in the Latin American countries. The Asian LDCs have however not been altogether immune to the phenomenon. For half a decade India's growth rate remained drastically lower than before after India vigorously accelerated its liberalisation and external orientation in 1991. In Pakistan too the rate of growth fell significantly in the period since the adoption of the reform programme in 1987. The decline in the rate of growth substantially weakened the force that offsets the adverse effect on poverty of increasing distributional inequity due to the employment hostility of growth that has been referred to above.

In most cases, stabilisation programmes led to drastic enough reductions in public expenditure to confront LDC governments with dilemmas as to how to distribute these reductions. In many countries the poor faced a reduced access to basic education, health and human capital. Once again China provides an illustration of reduced access of the poor to these services during a period of unprecedented growth and overall prosperity. ${ }^{20}$ There have of course been cases of countries which were able not only to preserve, but also to extend, the level of public expenditure that provides access of the poor to human capital, employment and basic services. Indonesia and Chile have been cited as prime examples.

In Pakistan, social sector expenditure as a proportion of total public expenditure fell after the adoption of the reform programme in $1987 .{ }^{21}$ Both in Pakistan and in India attempts were made to protect public expenditure that benefits the poor. The present writer knows of no reliable study that analyses the extent to which the governments in these countries succeeded in protecting or expanding the real level of benefits that public expenditure bestowed on the poor.

\section{Food Prices, Globalisation, and Poverty}

During the ISI period it was a widespread practice for the LDCs to artificially depress the price of food grains for the benefit of politically vocal urban middle class and the industrial entrepreneurs who wanted the cost of living of the industrial workers to remain low. The principal instrument for this was the manipulation of the trade regime, e.g., by a tax and/or quota on agricultural exports.

The reform of the trade regime dismantled much of these controls and often resulted in improved prices of agricultural products, including food. Available evidence suggests that the effect of this on the poor has been substantial though not the same everywhere. Thus the effect of a rise in food prices appears to be detrimental to poverty

\footnotetext{
${ }^{20}$ See Khan (1998).

${ }^{21}$ See Amjad and Kemal (1996).
} 
alleviation in India and the Philippines. The same was the experience of Indonesia in the 1970s. ${ }^{22}$

The effect of a rise in food prices is quite different in other cases. In Thailand, an improvement in agriculture's terms of trade, due to a reduction in the rate of negative effective protection, seems to reduce the incidence of poverty. In rural China too an improvement in producers' prices would have reduced the incidence of poverty. Indeed, one of the reasons that China's remarkable progress in reducing rural poverty drastically declined since the mid 1980s was a halt, and a periodic reversal, to the improvement in agriculture's terms of trade with which reforms in China began in $1979 .{ }^{23}$

The issue is extremely complex. First, it should be recognised that the effect of a rise in the price of food would depend on the structure of the economy. In an economy dominated by agriculture with an egalitarian peasant ownership there is a small incidence of net buyers of food among the poor. In this case a rise in agricultural prices, including the price of food, helps alleviate poverty by raising the income of the poor peasants. The effect is particularly strong if this comes about by way of abolishing discrimination against peasant exports. The poor in urban areas are adversely affected; but usually they are a numerical minority, often very small. Furthermore, a thriving rural economy should facilitate an acceleration of urban growth by providing both increased resources and additional demand for urban products. In an economy characterised by an inegalitarian agriculture, with a high concentration of net buyers of food among the poor, a rise in food price may easily aggravate the incidence of poverty. This may explain the asymmetrical effect of a rise in prices in China and India.

In Pakistan too food prices increased much faster in the period after reform than before. While food prices increased at roughly the same rate as overall prices in the years preceding reforms, their rate of increase in the years after the adoption of the structural adjustment programme is reported to have been higher than the rate of inflation. ${ }^{24}$ It is quite likely, given the unequal distribution of landownership in Pakistan, that this had an adverse effect on income distribution.

A second question is what to do when food prices are suppressed by distortionary policies even though it is known that a rise would adversely affect the poor. Macroeconomic reform may want to dismantle distortions-e.g., negative effective protection of agricultural exports and low procurement prices for food and agricultural goods in a regulated market-that reduce the efficiency of economic performance and adversely affect growth. It is quite possible that in the long run the adverse indirect effect on the poor, due to a reduction in economic growth, would outweigh the favourable direct effect of lower food prices. Furthermore, it should be

\footnotetext{
${ }^{22}$ The Indian case is documented in Tendulkar et al. (1996), the Philippines case in Balisacan (1996) and the Indonesia case in Booth (1996).

${ }^{23}$ The China case is documented in Khan (1998) and the Thailand case in Krongkaew (1996).

${ }^{24}$ See Amjad and Kemal (1996).
} 
possible to design some programme of compensating the net buyers of food among the poor for the adverse effect of a rise in food price by an expansion of employment through public works or targeted income subsidy or targeted public distribution of subsidised food.

\section{Foreign Direct Investment}

Contemporary Asian development experience does not indicate a uniform role for foreign direct investment. While the Republic of Korea (and Japan in an earlier period) developed with a degree of hostility towards foreign direct investment, other countries, notably Singapore, Malaysia, Indonesia and Thailand, have been far more friendly to it. Recent drive towards integration with the global economy has however witnessed a competition among the LDCs to attract foreign direct investment. While foreign direct investment has generally helped augment growth, it has often unleashed forces of inequality which have been detrimental to the interest of the poor. Once again China, with its phenomenal success in attracting well over half of all foreign direct investment going to the LDCs in recent years, provides an example. Most of these investments have been located in eleven rich coastal provinces and the capital, Beijing. Worse still, public policy has so single-mindedly pursued the goal of attracting foreign direct investment that it has ended up locating a disproportionate share of public investment in infrastructure in the rich provinces which had the greatest potential to attract foreign direct investment. This has resulted in an exacerbation of regional inequality to the detriment of the welfare of the poor who are mostly located in poor provinces with undeveloped infrastructure. ${ }^{25}$ China is by no means unique in this respect. Globalisation has resulted in the concentration of foreign direct investment and economic activity in general in the most developed regions in other countries as well, Vietnam being another outstanding example. ${ }^{26}$ It is highly likely that the same is happening in India, which has started to attract larger amounts of FDI, and the same will happen in other LDCs, like Pakistan, which achieve similar success.

\section{CONCLUSIONS}

As economic theory argues and the historical experience of East Asia testifies, integration with the globalising world economy, pursued within a carefully planned framework of orderly transition to a structure of production that is consistent with resource endowment, should be of advantage to the poor in the long run. It is however clear that the process of integration with the global economy also unleashes numerous forces of inequality that adversely affect the poor. It is naive to expect that the

${ }^{25}$ See Khan (1998).

${ }^{26}$ During 1988-95, 54 percent of foreign direct investment approved was located in and around Ho Chi Minh City and another 28 percent in Hanoi/Haiphong area according to IMF sources. 
distributional outcome of integration with the global economy in contemporary LDCs will be the same as that in the historical case of East Asia. The reason for the difference in outcome is largely due to the difference in initial conditions. The policy-makers should be alert to these forces. These are usually due to the inefficient initial structure of the economy which becomes unsustainable under the "rules of the game" in a globalising world economy. An example is the large concealed underemployment in (public) enterprises in the past, a phenomenon that can not be sustained under globalisation. The gradual elimination of this phenomenon leads to a low overall output elasticity of employment in manufacturing industries in the initial phase of otherwise successful integration with the world economy. Another example is the artificially low price of food that was often an integral part of the incentive system under the ISI strategy. Depending on the structure of the rural society, its elimination can prove disadvantageous to the poor.

A reversal of integration with the global economy is not the right answer to these problems. To do so would amount to depriving the economy of increased efficiency and opportunity for poverty reduction that globalisation could ultimately bring about. What the LDCs must do is to carefully manage the transition by implementing compensatory action in order to protect those among the poor who are hurt by the process of globalisation during the transition period. Examples of such policies are: (a) public works programmes, tied to the development of infrastructure and other productive activities, to protect the incrementally unemployed work force and the social groups that experience a disproportionate increase in cost of living; (b) protection of public expenditure that provides the poor with access to human capital and public services; and (c) targeted income subsidies to those poor groups which are unable to benefit from public works programmes.

The pursuit of foreign direct investment should be consistent with the social objective of limiting the disequalising effects of growth in the era of globalisation. A policy of decentralised development of infrastructure, based significantly on public works programmes, should be synchronised with the effort to decentralise the location of foreign direct investment. Recent Asian experience also points to the importance of managing capital flows in a way that irresponsible exposure to external borrowing is avoided.

Integration with the global economy within the framework of macroeconomic stabilisation of the extreme kind-leading to a collapse of economic growth or of the capacity to protect public expenditure that preserves the access of the poor to human capital and services - is inconsistent with the protection of the poor. This is demonstrated by the on-going experience of stabilisation in the Asian countries hit by the crisis of 1997. It is, however, clear-as amply demonstrated by the previous Indonesian experience of stabilisation in the early 1980s-that reasonably effective stabilisation can be consistent with the protection of the poor. There are components of 
public expenditure that can be eliminated with little adverse effect on the poor. The magnitude of such components is however often quite limited. An extreme programme of stabilisation must go beyond these options and adopt policies that hurt the poor. The success of Indonesian stabilisation in the early 1980s in avoiding an adverse effect on the poor was due to the avoidance of extreme stabilisation. This was possible because the donors made it possible for Indonesia to avoid a more extreme programme of stabilisation by permitting a reasonably high rate of capital inflow during the period of stabilisation. Much of the Latin American stagnation and immiserisation during the era of globalisation was due to the donor policy of reversing the direction of capital flow, i.e., subjecting Latin America to a net transfer to the rest of the advanced industrial countries. There is an important lesson for the donor community to learn from this experience. To avoid poverty-inducing integration of the LDCs with the global economy, they must pursue a policy of international resource flow that makes it possible for the LDCs to avoid an extreme retrenchment in public expenditure. Unfortunately, the experience of the recent Asian crisis does not demonstrate that the donors have learnt the right lesson in this regard.

\section{REFERENCE}

Amjad, R., and A. R. Kemal (1996) Macroeconomic Policies and their Impact on Poverty Alleviation in Pakistan. Pakistan Institute of Development Economics. (Manuscript.)

Asian Development Bank (1997) Emerging Asia: Changes and Challenges. Manila.

Balisacan, Arsenio (1996) Philippines: Policy Reforms and Poverty Alleviation. ILO/South-East Asia and Pacific Multidisciplinary Advisory Team (SEAPAT), Manila. (Manuscript.)

Boltho, Andrea (1994) China's Emergence-Prospects, Opportunities and Challenges. The World Bank: International Economics Department.

Booth, Anne (1996) Poverty in Indonesia. ILO/SEAPAT, Manila. (Manuscript.)

International Monetary Fund (IMF) (1996) Vietnam—Recent Economic Developments. Washington, D.C., December.

Khan, A. R. (1994) Overcoming Unemployment. Geneva: International Labour Organisation and the United Nations Development Programme.

Khan, A. R. (1995) A Quarter Century of Economic Development in Bangladesh: Successes and Failures. Bangladesh Development Studies. September-December.

Khan, A. R. (1996) Employment, Growth and Liberalisation: China's Growth in a Globalising World Economy. ILO/EASMAT, Bangkok. (Manuscript.)

Khan, A. R. (1997) Philippines: Employment in a Globalising and Liberalising World. Manila: ILO/SEAPAT.

Khan, A. R. (1998) Poverty in China in the Period of Globalisation: New Evidence on 
Trend and Pattern. International Labour Organisation, Geneva. (Issues in Development Discussion Paper 22.)

Khan, A. R., and M. Muqtada (eds) (1997) Employment Expansion and Macroeconomic Stability Under Increasing Globalisation. London: Macmillan.

Krongkaew, Medhi (1996) Macroeconomic Policies and Poverty: The Thai Experience. Bangkok: ILO East Asia Multidisciplinary Advisory Team.

Tendulkar, Suresh et al. (1996) Macroeconomic Policies and Poverty in India, 1966-67 to 1993-94. New Delhi: ILO/South Asia Multidisciplinary Advisory Team.

World Bank (1992) China: Strategies for Reducing Poverty in the 1990s. Washington, D. C.: World Bank.

World Bank (1992a) World Tables 1992. Baltimore and London: Johns Hopkins University Press.

World Bank (1995) World Tables 1995. Baltimore and London: Johns Hopkins University Press.

World Bank (1997) World Development Indicators 1997 (CD ROM). Washington, D. C.: World Bank. 